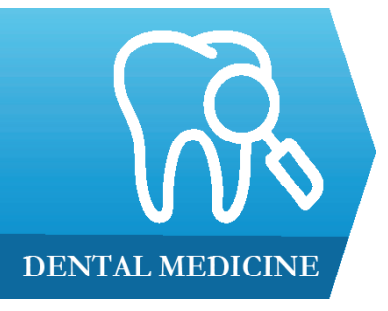

1) Department of Conservative Dentistry and Endodontics, Army College of Dental Sciences, Hyderabad, Telangana, India

2) Vidyaranyapuram, Mysore, Karnataka, India

DOI: $10.15386 / \mathrm{mpr}-1820$

Manuscript received: 22.07 .2020

Received in revised form: 29.09 .2020

Accepted: 26.10.2020

Address for correspondence:

pratyashakaushik2@gmail.com

This work is licensed under a Creative Commons Attribution-NonCommercialNoDerivatives 4.0 International License

\title{
Knowledge and perception of dental practitioners regarding the use of devitalizing agents
}

Pratyasha Kaushik ${ }^{1}$, Mamta Kaushik ${ }^{1}$, Elkanti Soujanya ${ }^{1}$, Roshni Roshni², Neha Mehra ${ }^{1}$, Lokam Karthik Prasad ${ }^{1}$

\begin{abstract}
Background. Pulpal pain is amongst the most severe pains experienced by humans. Various chemical agents are used routinely to devitalize the severely inflamed pulpal tissue. Most of these agents are harmful and have detrimental effects. This questionnaire-based study evaluated the awareness and perception of dental practitioners regarding the use of devitalizing agents during endodontic procedures, and various alternatives to minimize the use of these agents.

Methods. An open questionnaire was distributed to a total of 250 dental practitioners. It carried detailed information about the most common devitalizing agent used, the purpose of use, method, and duration of application, recommendations, complications encountered, awareness of complications, and various alternatives. The collected data were subjected to statistical analysis using SPSS (Statistical Package for Social Sciences) version 17.0 (IBM Statistics, Chicago, Illinois, USA). Descriptive statistics were drawn with respective percentages to have a comparative overview.

Results. 209 responses to 250 questionnaires circulated gave a response rate of $83.6 \%$. Amongst them, $63.15 \%$ of dentists were using devitalizing agents. The most widely and frequently used devitalizing agent was Devitec (PD Swiss, Vevey, Switzerland) (36.3\%), followed by Caustinerf forte (Septodont, Saint-Maur-des-Fosses, France) (29.5\%). A total of $32.9 \%$ dentists were aware of the recommendations, and $66.02 \%$ were aware of the complications of devitalizing agents; $16.26 \%$ of dental practitioners encountered complications due to the use of devitalizing agents. The dentists listed the alternate methods regarding the use of pulp devitalizing agents.

Conclusion. Although most of the dentists were aware of the harmful effects and few encountered complications with the use of devitalizers, they continued to use these agents because of the lack of an effective alternative.
\end{abstract}

Keywords: formocresol, surveys and questionnaires, pulpitis, pain

\section{Introduction}

Pain is an unpleasant multifactorial, multidimensional experience that causes physical and emotional discomfort [1]. It is the most common reason for which a patient seeks dental treatment. Therefore, pain control holds the highest priority in the dental profession. A study by Lipton et al. showed that toothache has the highest prevalence among orofacial pains [2].

Pulpal pain is amongst the most severe pains experienced by humans. It occurs due to the activation of nociceptive fibers in response to inflammatory changes caused by various etiological factors like caries, trauma, tooth wear, and iatrogenic factors [3]. Endodontic therapy aims to control pain, treat pulpal and periradicular disease.

Most dental procedures are performed under local anesthesia to achieve adequate pain control [4]. Profound anesthesia is attainable in asymptomatic teeth. However, teeth exhibiting symptomatic irreversible pulpitis and undergoing root canal therapy (RCT) are challenging to anesthetize as there is a high rate of failure in achieving pulpal anesthesia. Rate of anesthetic failure ranges from $17 \%$ (mandibular second molar) to $58 \%$ (mandibular central incisor) [5]. 
Various chemical agents containing formaldehyde, cresol, paraformaldehyde, and arsenic compounds have been used to devitalize severely inflamed pulpal tissue when anesthesia is inadequate [6]. These devitalizers fix and necrotize the pulpal tissue easing out pain as well as facilitating painless second appointments. However, these agents are known for their deleterious effects on surrounding tissues.

In the past, the use of arsenic-based compounds was widespread; however, they have proven to possess many hazardous effects on periapical tissues and the supporting bone [7]. Non-arsenic based compounds that include formaldehyde and its variants have replaced these agents. Although these agents are useful in the palliative treatment of dental pain, many case reports demonstrate unfavorable adverse effects ranging from gingival sloughing to alveolar bone necrosis or localized osteomyelitis [6-10]. Also, formaldehyde is known for its toxic, mutagenic, and carcinogenic potential. Investigations conducted to measure the risk of exposure to formaldehyde, found that formaldehyde poses a carcinogenic and toxic risk in humans [11]. Formocresol is not recommended for human use by the American Association of Endodontists and the American Association of Pediatric Dentistry [12]. Hence, the use of devitalizing agents is no longer indicated and recommended [11-13].

Despite the above mentioned detrimental effects, dentists use these agents routinely in their dental practice $[14,15]$. Thus, it is essential to highlight the effects of devitalizing agents and to know the behavior of dentists regarding the use of these products. The present study aimed to evaluate the awareness and perception of dental practitioners toward devitalizing agents during endodontic procedures and also various alternatives to minimize the use of these agents.

QUESTIONNAIRE

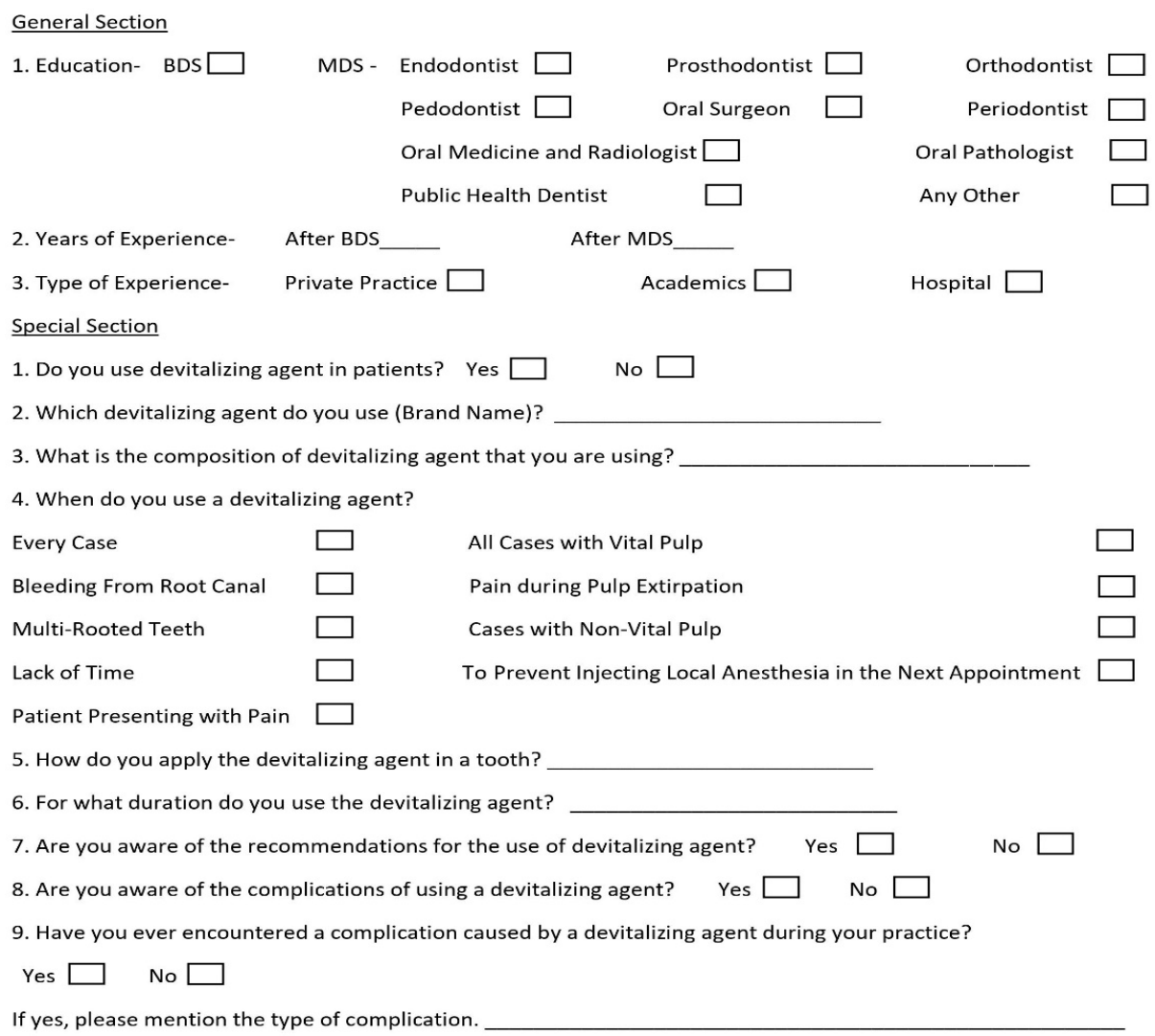

If yes, please mention the type of complication

10. How did you manage that complication and what was the prognosis?

11. What according to you can be an alternative to a devitalizer?

Figure 1. Sample of the questionnaire used in the present survey. 


\section{Methods}

\section{Study Design}

This study was an observational, questionnairebased survey conducted from June to August 2018.

\section{Participants}

The survey was conducted among 250 dental practitioners in Hyderabad city of Telangana state, India. The participants included general dentists or specialists in private practices or employed in a hospital.

\section{Questionnaire}

An open questionnaire consisting of two sections, a general section and a special section, was designed (Figure 1). The general section included information on the participants, such as qualification, experience (years) and type of practice (private practice, academics, or hospital). The confidentiality of name, age, and gender of the respondents was maintained. The special section consisted of 11 questions related to the use of devitalizing agents.

The respondents were asked about the most common devitalizing agent that they used, its purpose, method, and duration of application. Questions included awareness of recommendations regarding the use of devitalizing agents, type of complications encountered during practice (if any), and its management. Alternatives to devitalizing agents were also included.

\section{Statistical analysis}

The collected data were subjected to statistical analysis using SPSS (Statistical Package for Social Sciences) version 17.0 (IBM Statistics, Chicago, Illinois, USA). Descriptive statistics were drawn with respective percentages to have a comparative overview.

\section{Results}

The response rate was $83.6 \%$. Most of the practitioners had a professional experience of $1-5$ years $(62.67 \%)$ followed by 6-10 years $(21.05 \%)$. From the 250 participants, $27.2 \%$ were Bachelor of Dental Surgery (BDS) practitioners and $72.72 \%$ were Master of Dental Surgery (MDS) of which $29.1 \%$ were endodontists and the rest belonged to other specialties.

In the present survey, $63.15 \%$ of the participants used devitalizing agents, of which $78.94 \%$ were BDS practitioners, $92 \%$ were pedodontists, and $63.93 \%$ were endodontists. The most widely used devitalizing agent was Devitec $(36.3 \%)$, followed by Caustinerf forte $(29.5 \%)$. The majority of dentists $(60.02 \%)$ were aware of the complications of these agents, but only $32.5 \%$ were aware of the recommendations (Table I).

Regarding the duration of the devitalizing agents application, $75 \%$ placed it for $1-7$ days, $16.66 \%$ for 8-10 days, and $8.33 \%$ for less than one day. None of the dentists used these agents for more than ten days (Table II). The most common purpose stated was pain during pulp extirpation $(37.30 \%)$, followed by the patient presenting with pain $(20.09 \%)$, and lack of time (18.18\%).
Table I. Number of dentists who are aware of complications and recommendations.

\begin{tabular}{|c|c|c|}
\hline Education & $\begin{array}{c}\text { No. of dentists aware of } \\
\text { the recommendations }\end{array}$ & $\begin{array}{c}\text { No. of dentists aware } \\
\text { of complications }\end{array}$ \\
\hline $\begin{array}{c}\text { BDS } \\
\text { 27.20\% }\end{array}$ & $11(19.29 \%)$ & $34(59.64 \%)$ \\
$\begin{array}{c}72.72 \% \\
\text { Total }\end{array}$ & $57(37.5 \%)$ & $104(68.42 \%)$ \\
\hline
\end{tabular}

Table II. Duration of application of devitalzing agent.

\begin{tabular}{l|c}
\hline Duration & Percentage of Participants \\
\hline Less than 1 day & $8.33 \%$ \\
1-7 days & $75 \%$ \\
$8-10$ days & $16.66 \%$
\end{tabular}

There were $16.26 \%$ of dental practitioners encountering complications because of the use of devitalizing agents. The most frequently encountered complications were gingival necrosis and sloughing (Table III).

Table III. Type of complications encountered.

\begin{tabular}{lc} 
Type of complication encountered & Number \\
\hline Pain and gingival inflammation & 6 \\
Gingival necrosis and sloughing & 20 \\
Burn/ Ulceration & 5 \\
Allergic reaction & 2 \\
Periapical tissue necrosis & 1 \\
Total & $34(16.26) \%$
\end{tabular}

The dentists also listed alternatives to these agents (Table IV). The commonly suggested alternatives were a proper and effective use of local anesthesia, followed by using intrapulpal anesthesia, complete extirpation of pulp in the first appointment, and copious sodium hypochlorite $(\mathrm{NaOCl})$ irrigation.

Table IV. Various alternatives to a devitalizing agent.

$\begin{array}{lc}\text { Alternative to a devitalizing agent } & \text { Number } \\ \text { Place cotton soaked in local anesthetic agent } & 01(1.08) \% \\ \text { Polyantibiotic paste } & 01(1.08) \% \\ \text { Intra-pulp-anesthesia } & 17(18.47) \% \\ \text { Proper and effective local anesthesia } & 25(27.17) \% \\ \text { Formocresol } & 05(5.43) \% \\ \text { Single sitting Root Canal Treatment } & 04(4.34) \% \\ \text { Premedication with Non-Steroidal Anti- } & 02(2.17) \% \\ \text { Inflammatory Drugs } & 12(13.04) \% \\ \text { Complete extirpation of pulp in } 1^{\text {st }} \text { appointment } & 12(13.04) \% \\ \text { Copious Sodium Hypochlorite irrigation } & 01(1.08) \% \\ \text { Formaldehyde } & 03(3.26) \% \\ \text { Complete cleaning and shaping in } 1^{\text {st }} \text { appointment } & 05(5.43) \% \\ \text { Anticoagulants } & 01(1.08) \% \\ \text { Paraformaldehyde free agents } & 01(1.08) \% \\ \text { Regular treatment } & 02(2.17) \%\end{array}$




\section{Discussion}

A survey is a vital tool for collecting information from or about a given population to describe and compare their knowledge attitude and behavior [16]. A questionnairebased survey has the advantage of allowing respondents to answer questions in their time [17]. The present questionnaire-based survey was conducted amongst 250 dental practitioners in Hyderabad city of Telangana state, India, to assess their perception and knowledge towards the use of devitalizing agents. Various alternative techniques for devitalizing pulpal tissues were also assessed through this survey. A response rate of $83.6 \%$ was received.

Similar surveys in the past evaluating the practice and nature of endodontic therapy received a response rate ranging from $97 \%$ to $41.5 \%$ [14,15,18-20]. The excellent response for the present survey could be the ease of circulation of the questionnaire and response through an online link, the possibility to complete the questionnaire in less than 6 minutes, and blinding of names.

Even though the harmful effects of paraformaldehyde are well documented, a tendency for user-friendly alternatives takes precedence over seemingly farfetched harms. The present study was to evaluate the prevalence in the usage of devitalizers amongst the dentists. Moreover, through questionnaire create consciousness and curiosity towards alternatives.

In the current study, where $62.67 \%$ of the respondents had 1 to 5 years experience, $63.15 \%$ of respondents used devitalizing agents, which is lower than a previous study conducted in India in 2015, where $77 \%$ of respondents were using these agents [14]. The primary purpose of using devitalizing agents was to control pain during pulp extirpation (37.30\%). This shows that dentists use devitalizing agents to alleviate pain, thus increasing patient cooperation and reducing treatment time. In the current scenario of the Covid-19 outbreak, Meng et al. have suggested using devitalizing agents during the emergency treatment of cases diagnosed with symptomatic irreversible pulpitis [21].

The knowledge about complications arising from use of devitalizers was $60.02 \%$, comparable to the previous survey, where $67 \%$ of the respondents were aware of the same [14]. $16.26 \%$ of the respondents listed complications encountered during their practice [6-10].

Verma et al. reported a case of soft tissue desquamation and gingival necrosis, developing within 24 hours following the use of formocresol during endodontic treatment of left maxillary first premolar [22]. Animal experiments have shown that formaldehyde gets systemically distributed after pulpotomy procedures using formocresol. Reports from animal studies suggest that formaldehyde has mutagenic and carcinogenic potential. It has also been demonstrated that formocresol leads to immune sensitivity due to the formation of antibodies. Due to the findings mentioned above, the International Agency for Research on Cancer of the World Health Organization reclassified formaldehyde as a known human carcinogen in 2004 [23]. The American Association of Endodontists and the American Association of Pediatric Dentistry do not recommended formocresol for human use [12]. In the present study, only $32.5 \%$ of the respondents were aware of these recommendations.

Devitalizers should be used as per the manufacturer's instructions. Applying these agents in small quantities in the pulp chamber is recommended for not more than seven days [24-27]. Furthermore, they should not leach from the preparation; hence the tooth preparations should be adequate [9]. A majority of the dentists in this study followed this. Through this, it can be inferred that most of the dental practitioners are well informed about the correct usage of devitalizing agents.

This study asked the participants to suggest alternatives to devitalizers. Most of them suggested the proper and effective use of local anesthesia and intrapulpal anesthesia to overcome pain during endodontic therapy. Other supplemental anesthetic techniques such as intraligamentary and intraosseous can also be used in cases of hot tooth. Also, alternative anesthetic agents like $4 \%$ prilocaine, $3 \%$ mepivacaine, $4 \%$ articaine, $0.5 \mathrm{M}$ Mannitol (in combination with lidocaine) and long acting anesthetics can be used to achieve profound anesthesia [5]. All suggestions were directed towards enhancing anesthesia, further reinforcing the use of devitalizer as a means to control the acute pain. Future research can be directed towards finding alternatives to control pain effectively in the cases of irreversible pulpitits, where pain control is a challenge. Lasers and electrocautery as possible alternatives, can be explored for devitalizing pulpal tissues $[28,29]$. None of these methods were projected by the respondents as an alternative in this survey. This could be due to the limitations of lasers, such as high cost, technique sensitivity, and lack of training and updates among dental practitioners [28].

The limitation of this study was that dentists who preferred alternatives over devitalizing agents had not been analyzed.

\section{Conclusion}

Two hundred and fifty practitioners were surveyed, of which only $60.02 \%$ had knowledge about the complications arising from the use of devitalizers and viable alternatives. There is a need to increase awareness on the complications for pulp devitalization. The use of traditional agents with known complications should be regulated and further research should focus on developing alternatives.

\section{References}

1. Peters OA, Peters CI. Cleaning and shaping of the root canal system. In: Kenneth M. Hargreaves, Louis H. Berman, Ilan 
Rotstein, eds. Cohen's Pathways of the Pulp. Missouri: Elsevier Health Sciences; 2015. p. 209-270.

2. Lipton JA, Ship JA, Larach-Robinson D. Estimated prevalence and destribution of reported orofacial pain in the United States. J Am Dent Assoc 1993;124:115-121.

3. Abd-Elmeguid A, Yu DC. Dental pulp neurophysiology: part 1. Clinical and diagnostic implications. J Can Dent Assoc. 2009;75:55-59.

4. Moore PA, Hersh EV. Local anesthetics: pharmacology and toxicity. Dent Clin North Am. 2010;54:587-599.

5. Reader AL, Nusstein J, Khan A. Pain control. In: Kenneth M. Hargreaves, Louis H. Berman, Ilan Rotstein, eds. Cohen's Pathways of the Pulp. Missouri: Elsevier Health Sciences; 2015. p. 90-122.

6. Srivastava A, Gupta KK, Tandon P, Rajpal J. Necrosis of alveolar bone secondary to endodontic treatment and its management. J Interdiscip Dentistry. 2011;1:41-44.

7. Giudice A, Cristofaro MG, Barca I, Novembre D, Giudice M. Mandibular bone and soft tissues necrosis caused by an arsenical endodontic preparation treated with piezoelectric device. Case Rep Dent. 2013;2013:723753.

8. Chen G, Sung PT. Gingival and localized alveolar bone necrosis related to the use of arsenic trioxide paste--two case reports. J Formos Med Assoc. 2014;113:187-190.

9. Lee $\mathrm{CH}$, Choi Y, Park S. Mandibular bone necrosis after use of paraformaldehyde-containing paste. Restor Dent Endod. 2016;41:332-337.

10. Tortorici S, Burruano F, Difalco P. Maxillary bone necrosis following the use of formaldehyde containing paste: management and case series. Br Dent J. 2007;203:511-512.

11. Lewis BB, Chestner SB. Formaldehyde in dentistry: a review of mutagenic and carcinogenic potential. J Am Dent Assoc. 1981;103:429-434.

12. Alkhatib Z, El Abed R. Complications due to medicaments. In: Priyanka Jain ed. Common Complications in Endodontics: Prevention and Management. Cham: Springer, 2008, p. 149176.

13. Zhang L, Steinmaus C, Eastmond DA, Xin XK, Smith MT. Formaldehyde exposure and leukemia: a new meta-analysis and potential mechanisms. Mutat Res. 2009;681:150-168.

14. Walimbe H, Kontham U, Bijle MN, Wani V, Nankar M, Muchandi S. Knowledge, attitude and practice of devitalizing agents: a survey of general dental practitioners. J Int Oral Health. 2015;7:12-14.

15. Unal GC, Kaya BU, Tac AG, Kececi AD. Survey of attitudes, materials and methods preferred in root canal therapy by general dental practice in Turkey: Part 1. Eur J Dent. 2012;6:376-384.

16. Fink A. The survey handbook. London: Sage; 2003. p. 1-2.

17. Mathers N, Fox N, Hunn A. Surveys and questionnaires. Trent: RDSU. 2007.

18. Ahmed MF, Elseed AI, Ibrahim YE. Root canal treatment in general practice in Sudan. Int Endod J. 2000;33:316-319.

19. Che Ab Aziz ZA, Abdullah M, Vello CDS, Thangavelu K. General dental practitioners' knowledge and practice on root canal treatment. Annals of Dentistry University of Malaya. 2006;13:12-17.

20. Jenkins SM, Hayes SJ, Dummer PM. A study of endodontic treatment carried out in dental practice within the UK. Int Endod J. 2001;34:16-22.

21. Meng L, Hua F, Bian Z. Coronavirus disease 2019 (COVID-19): emerging and future challenges for dental and oral medicine. J Dent Res. 2020;99:481-487.

22. Verma P, Chandra A, Yadav R. Endodontic emergencies: Your medication may be the cause. J Conserv Dent. 2009; 12:77-79.

23. Jose B, Ratnakumari N, Mohanty M, Varma HK, Komath M. Calcium phosphate cement as an alternative for formocresol in primary teeth pulpotomies. Indian $\mathrm{J}$ Dent Res. 2013;24:522.

24. ProduitsDentaires SA. The Devitec Brochure. Available from: http://www.vallexm.ru/files/Stomatology_PD/ Devitec_11402.pdf.

25. Septodont. The Caustinerf Arsenical Brochure. Available from: http:/www.universaldental.com.pk/documents/ Caustinerf-Arsenical.pdf.

26. Tehno Dent. The Devital Brochure. Available from: http:// www.tehnodent.org/en/assets/template/files/EC/016-00202-devital.pdf.

27. Septodont. The Caustinerf Deciduous Brochure. Available from: https://www.septodont.co.uk/sites/default/files/ Caustinerf\%20Deciduous\%20Patient $\% 20$ information $\% 20$ leaflet $\% 20$ S $\% 2005 \% 2006 \% 20005 \% 2047 \% 2000$.pdf.

28. Najeeb S, Khurshid Z, Zafar MS, Ajlal S. Applications of Light Amplification by Stimulated Emission of Radiation (LASERS) for Restorative Dentistry. Med Princ Pract. 2016;25:201-211.

29. Jurič IB, Anić I. The use of lasers in disinfection and cleanliness of root canals: a review. Acta Stomatol Croat. 2014;48:6-15. 